\title{
Article \\ The Effect of Training in Virtual Reality on the Precision of Hand Movements
}

\author{
Sergo Martirosov, Petr Hořejší * (D), Pavel Kopeček, Marek Bureš and Michal Šimon (D)
}

check for updates

Citation: Martirosov, S.; Hořejší, P.; Kopeček, P.; Bureš, M.; Šimon, M. The Effect of Training in Virtual Reality on the Precision of Hand Movements. Appl. Sci. 2021, 11, 8064. https:// doi.org/10.3390/app11178064

Academic Editor:

Giuseppe Marannano

Received: 13 August 2021

Accepted: 27 August 2021

Published: 31 August 2021

Publisher's Note: MDPI stays neutral with regard to jurisdictional claims in published maps and institutional affiliations.

Copyright: (c) 2021 by the authors. Licensee MDPI, Basel, Switzerland. This article is an open access article distributed under the terms and conditions of the Creative Commons Attribution (CC BY) license (https:// creativecommons.org/licenses/by/ $4.0 /)$.
Department of Industrial Engineering and Management, University of West Bohemia, Univerzitní 2732/8, 30100 Plzeň, Czech Republic; martiros@kpv.zcu.cz (S.M.); kopecek@kpv.zcu.cz (P.K.); buresm@kpv.zcu.cz (M.B.); simon@kpv.zcu.cz (M.Š.)

* Correspondence: tucnak@kpv.zcu.cz

\begin{abstract}
The main point of the work was to use virtual reality to discover its benefits on training, specifically on the precision of hand movements in specific settings, and then evaluate its effects both for virtual reality and the transfer of the results to the real world. A virtual reality simulation was created using the Unity3D game engine and real-world experimental material was also prepared. A total of 16 participants took part in the training, which lasted for approximately one month. Once the data was gathered from both the virtual reality and real-world tests, we carried out in-depth statistical analysis. The results suggest positive outcomes in most aspects in virtual reality training productivity, but only partial transfer of the training benefits to the real world scenario. The possible reasons for this are described in the work and suggestions are given to duplicate the study with different variables to try to achieve different results.
\end{abstract}

Keywords: virtual environments; training; manuals and instructions; controls and input devices; human error

\section{Introduction}

VR technology is used in different areas of life for various purposes. VR is the most immersive type of reality technology that creates an artificial environment to inhabit. This immersive, computer-generated environment blocks out sensory input from the outside world and uses visual and auditory cues to make the virtual world seem quite real. It is immersive because of its simulated environment that manages to trick your subconscious mind to start treating this illusion as real.

The main point of this work is to perform an experiment in VR and RW and find out if precision, accuracy and time factors change and, if so, by how much and in which direction. Accuracy and precision are alike only in the fact that they both refer to the quality of measurement, but they are very different indicators of measurement. Accuracy is the degree of closeness to the true value, whereas precision is the degree to which an instrument or process will repeat the same value. In other words, accuracy is the degree of veracity while precision is the degree of reproducibility [1].

This work focuses on just one way of measuring the precision of hand movements using one specific type of simulation, but the types of training simulations for each job should definitely have their own variants and styles of simulation. Some examples of professions that require high hand-to-eye coordination and precision are given below. VR training in these cases could drastically improve the skills required to perform the tasks, as it would allow unlimited training in any circumstances.

VR technology has become very popular and is used in many different areas such as entertainment, military, healthcare, education, engineering, etc. VR is a simulated environment that is created with computer technology and presented to the user in such a way that the user starts to feel as if they are in a real environment. A simulation is a model of the RW wherein the user has the ability to interact with the environment [2]. Simulations 
are helpful and useful as they provide a realistic context in which individuals can explore, experiment and see immediate results as they create models of their own or try theories on the modelled concept [3]. Depending on the number of senses simulated in VR, such as vision, hearing, touch, balance, even smell, the immersion level in the artificial world can vary.

The technological advances of computer hardware and software have made it possible to incorporate 3D Virtual Reality in innovative applications for teaching, training, and learning [4-6]. It has been noted that there is a strong potential value of ergonomics for virtual environments and vice versa [7]. A virtual environment or virtual world is a computer-generated 3D representation of real or fictional environments. A user can interact in such an environment independently at the same pace as one would experience events in the real world [8]. VR can support realistic and immersive simulation and enables the transfer of skills taught in VR into real contexts, as well as the provision of multi-user, embodied, and interactive active learning [9]. VR is believed to be a promising tool for training and complex problem solving, where weighing multiple variables and situational decision making are required [9-12]. Not only VR but also augmented reality (AR), which is often used in combination with or supplemented by VR, has been studied intensively and proven to be a useful training tool. One study [13] suggests using virtual training with augmented reality in assembly tasks as it can greatly reduce the time taken to perform assembly tasks compared to classical methods. Having skilled and trained employees is very important, and a study [14] proposed brand new smart solutions for designing and presenting work instructions and showed a comparison of different types of virtual, augmented, and conventional assembly instructions. The results of the research show promising future potential.

One of the uses of VR can be helping those with autism to lessen social anxiety and frustration and improve academic and social skills. Individuals with autism suffer from the impairment of social functions, which leads to difficulties in social interaction, communication, and emotion recognition $[15,16]$. The fact that VR systems can allow users to explore immersive 3D environments from any location at any time could have a profound impact on science education [17]. VR allows the exploration of hidden phenomena and distant locations and the manipulation of otherwise immutable objects [18]. For instance, VR gives medical students the possibility to explore delicate internal organs that would otherwise require cadaver dissection [19].

When working with VR applications, it is important to understand that eventually the problem of cyber sickness arises, and it is very helpful to know where it is coming from and how to combat it if possible. Visually induced motion sickness is a syndrome that occasionally occurs when physically stationary individuals view compelling visual representations of self-motion. It may also occur when detectable lags are present between head movements and recomputation and the presentation of the visual display in helmetmounted displays [20]. When creating a simulation in VR, thinking ahead about all the potential factors that could negatively influence participants in any way is crucial, as cyber sickness can have negative effects on experimental results. Research suggests there are various relationships between different factors, such as VR training experience, engagement, immersion, etc. and the level of stress from training in VR [21]. Thus, having that and other factors influencing cyber sickness in mind, we tried to create a VR training simulation that was as simple and easy as possible. There is also evidence that the weight of the head-mounted display can cause discomfort in the users' necks and shoulders, and if participants have to rotate their heads due to an activity in VR, their discomfort level grows [22]. In our training the participants had to simply stand in one place and look down at the table where the shape models were located. Rotation of the head was not required. We tried to minimize this and other factors that could cause VR sickness. As cyber sickness is very similar to motion sickness, there are many aspects that they share, thus making it possible to borrow some solutions from motion sickness and apply them to cyber sickness. 
There is a wide variety of research being conducted in the field of VR on cyber sickness: cyber sickness in different types of moving images [23], comparison of one-screen and three-screen displays [24,25], relationship between age and sickness level [26], and a gender effect on cyber sickness [27,28]. Research on virtual environments (VEs) has provided converging evidence that being placed in a VE with a head-mounted display (HMD) can lead to motion sickness (MS) [29] Previous studies suggest that a twentyminute exposure to VREs (virtual reality environments) can increase cyber sickness (CS) symptoms in over $60 \%$ of participant [30]. It has been noted that some users might exhibit symptoms of CS, both during and after experiencing VR [31,32]. CS is different from MS in that the users are stationary, but they have a compelling sense of motion as the visual imagery changes $[33,34]$.

Currently there is a debate concerning VR technology and VR cyber sickness. Some argue that the problem of VR sickness is inherent in this technology itself and that as long as there is mismatch between what is visually perceived and what is physically sensed, fixing the VR display properties will not address the root cause [35].

\section{Materials and Methods}

\subsection{Software and Hardware Equipment}

The VR simulation was created using the Unity3D game engine. The tests were run on a VR-ready Acer Predator notebook, with Intel Core i7-6700HQ @ 2.60 GHz, 16 gb Ram and Nvidia GeForce GTX 1060-6gb. The VR headset was a HTC Vive Pro, which has a resolution of $1440 \times 1600$ pixels per eye $(2880 \times 1600$ pixels combined), a $90 \mathrm{~Hz}$ refresh rate, and a 110 degrees field of view. All of these parameters allowed participants to have as comfortable a VR experience as possible.

\subsection{Design}

The environment in VR was a simple room with no extra objects in it, in order not to distract participants with unnecessary visual noise (see Figure 1). Apart from the room itself, the only 3D models available in the scene were a $1.05 \mathrm{~m}$ high table, an object (line, circle, sinus wave) of reference to draw on, a model of a glue gun or caulking gun, depending on the scene, which was either a one-handed or two-handed version. The line, circle, and sinus wave were green with medium transparency on them, whereas the drawing was done with opaque yellow with Unity3D's line renderer.

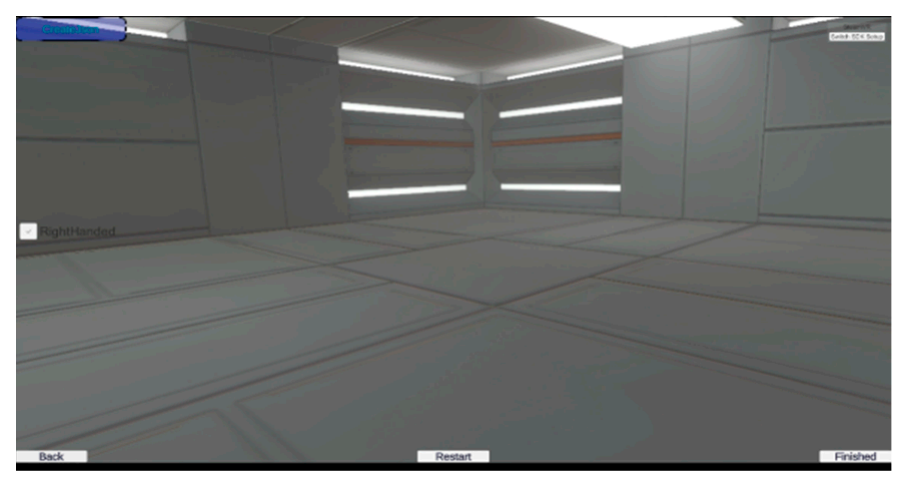

Figure 1. Empty VR environment.

The laboratory with assigned VR tracking space can be seen in Figure 2. 


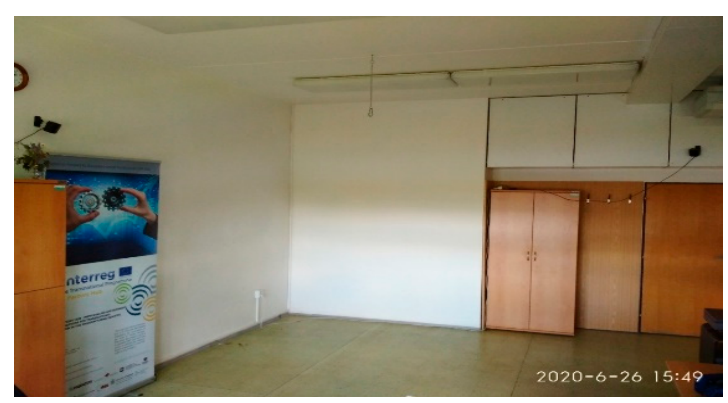

Figure 2. Space for VR testing with tracking stations.

\subsection{D Models}

The models of the glue gun (see Figure 3) and caulking gun (see Figure 4) were first downloaded from the web and slightly adjusted in Blender software for our experiment.

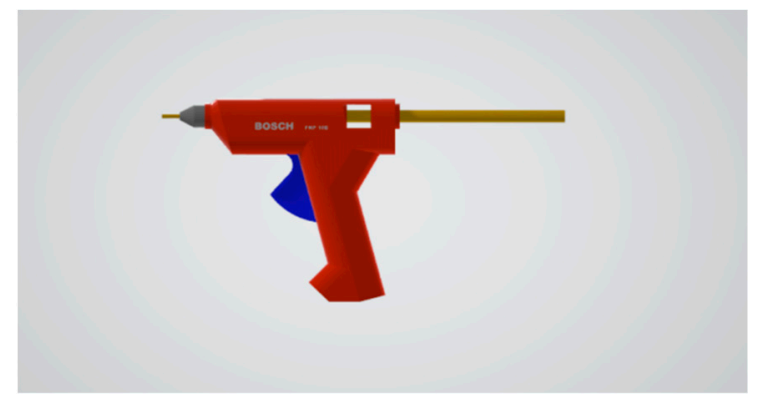

Figure 3. Glue gun model in 3D Viewer.

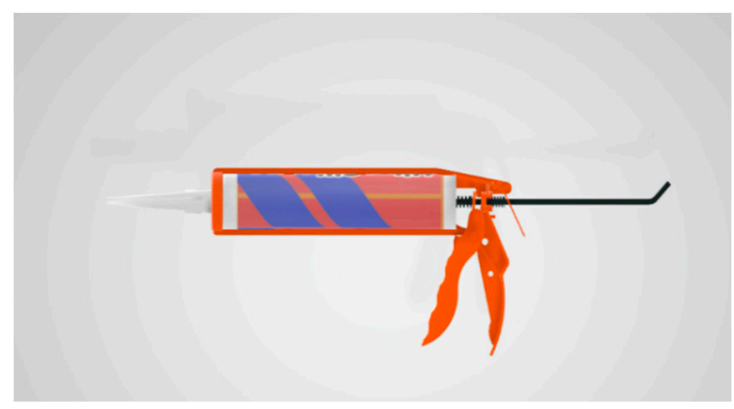

Figure 4. Caulking gun model in 3D Viewer.

\subsection{Shape Models}

Line, circle, and sine wave models were modelled in Blender software using curve objects and were very thin, in order to create a strict movement pattern that participants had to follow (see Figures 5-7). The thinner the objects were, the less would be the scatter in precision.

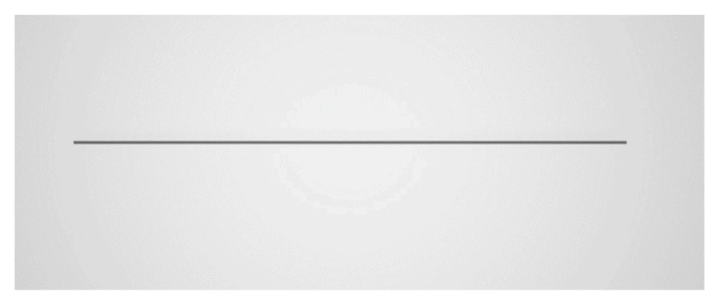

Figure 5. Line model in 3D Viewer (default grey/unchanged colour). 


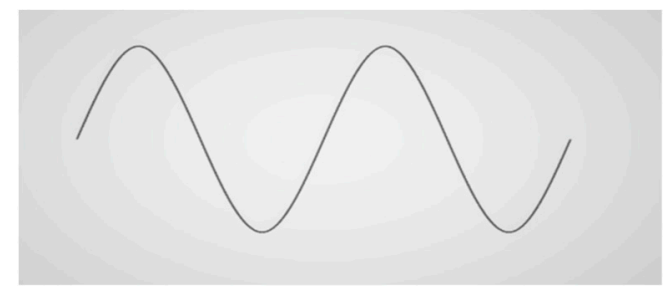

Figure 6. Sinus wave model in 3D Viewer (default grey/unchanged colour).

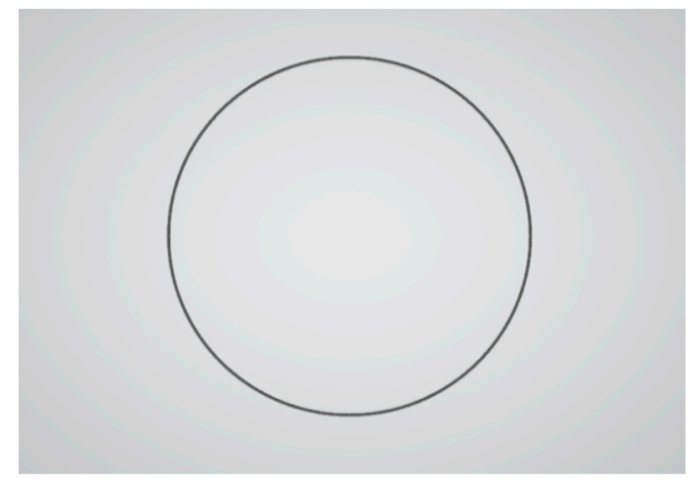

Figure 7. Circle model in 3D Viewer (default grey/unchanged colour).

\subsection{Procedure}

One session lasted around 20-25 min, depending on the participants' abilities. Each participant was instructed to draw with the glue gun (one hand) and caulking gun (both hands) following the line on the table, as precisely and as quickly as possible, but it was completely up to them which of the two aspects (precision or speed) they would choose over the other. They just needed to do it the best way they could.

Participants were handed HTC Vive Pro controllers and placed in a specific location in the real environment, so that the tracking stations could follow their hand movements throughout the whole experiment to avoid any jitter or freeze. Despite having the best conditions, this still happened sometimes, so the drawing on which the tracking was jittery had to be erased and redone. Using specialized gloves/trackers for such experiments/tasks is the ideal situation as it provides maximum precision. But in this case, two Vive tracking stations were used to track the hand movements in VR. The lighting and positioning of the users during the experiment were taken into account; both tracking stations had clear views of the participant, and the lighting in the room was also enabled to sufficient levels. The drawing started on button press and finished on button release.

Once the VR scene started, participants would be 'spawned' right in front of the table, as everything was positioned (both in VR and the RW) in a way to make the experience for participants as comfortable as possible. The experiment was conducted in such a way that all the objects required for the experiment (and there were no extra objects in the environment) were located right in front of the user, at the closest possible distance. So when it comes to the potential problem of stereopsis (difficulty focusing on farther objects), in this particular case, everything was done in such a way so that the users could easily focus on the task at hand and the objects in front of them. The drawing was done using Unity3D game engines line renderer component, which draws points on the position of the glue gun or caulking gun edge when the VR controller movement changes and the button is pressed. The distance at which the points could be drawn was adjusted in such a way that, when drawn, the points were so close to each other that it created the illusion of a continuous yellow line. If the distance was adjusted for higher values, such as $1 \mathrm{~cm}$, the points would be drawn $1 \mathrm{~cm}$ apart from each other while the participant held the controller and drew in VR, and with this big distance between points, there would be no continuous line, but simply points in 3D space. Additionally, the more points there were, the more 
accurate the data that could be obtained. In this experiment, the distance was less than a millimetre. The smaller the distance between the point centres, the more points would be drawn.

Time and distance were automatically calculated using our own Unity3D VR simulation. There is no need to consider the subjective time compression factor [36], as we are obtaining only objective real data.

\subsection{Results}

Figures 8-13, which are the results from the VR experiment, show the trends in the results after 7 sessions of the experiment from all the users' combined data, which is the average distance (millimetres) between the drawn points and the actual static 3D objects (line, circle, sine) and the average time in seconds it took to perform each task. The trend towards less distance between the points and objects is better. The same goes for the time requirements to perform the tasks.

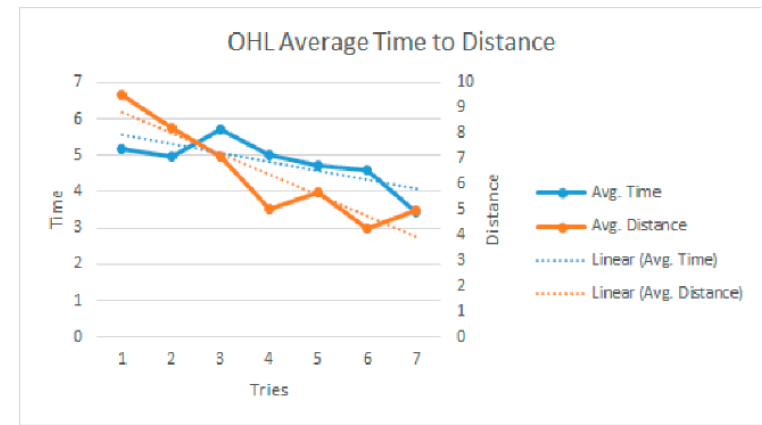

Figure 8. One hand line avg. time to distance trend.

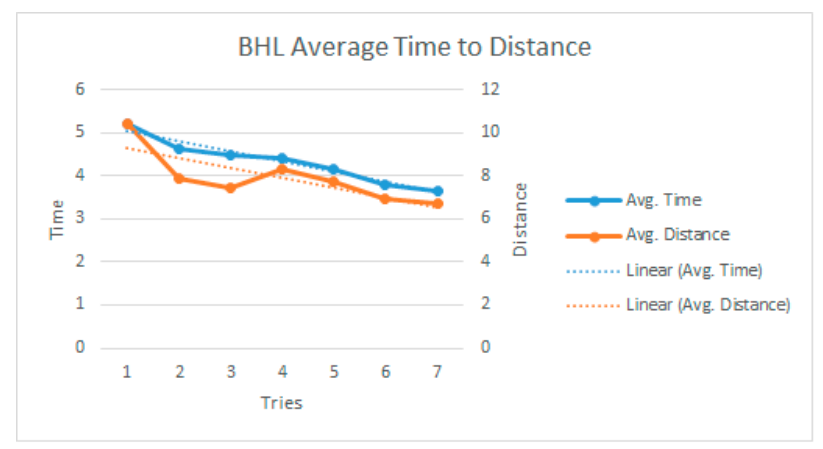

Figure 9. Both hands line avg. time to distance trend.

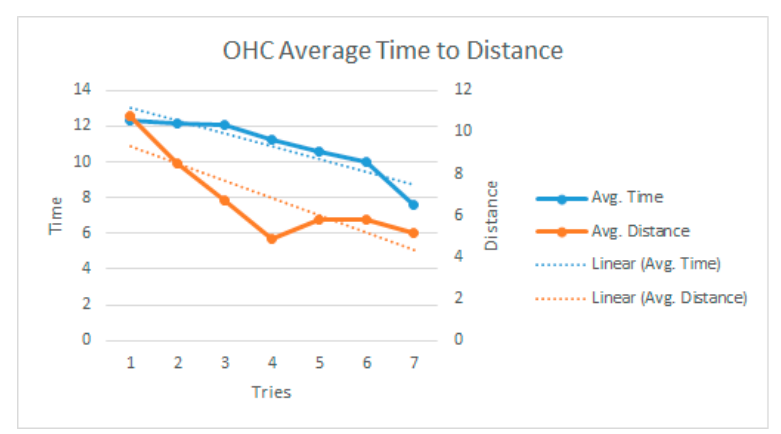

Figure 10. One hand circle avg. time to distance trend.

From the graphs above, it can clearly be seen that all the results from one hand and both hands VR experimental results of average time and distance improved from the first day all the way to the last. It can even be concluded that, in VR, no more than 4 sessions are 
required, as, after the 4th session, the trend of improvement slowed down, thus indicating that the benefits were sufficient right up until that point.

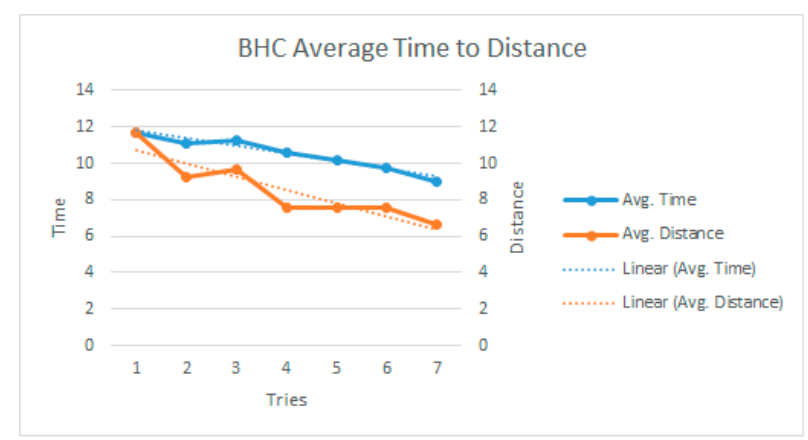

Figure 11. Both hands circle avg. time to distance trend.



Figure 12. One hand sine avg. time to distance trend.

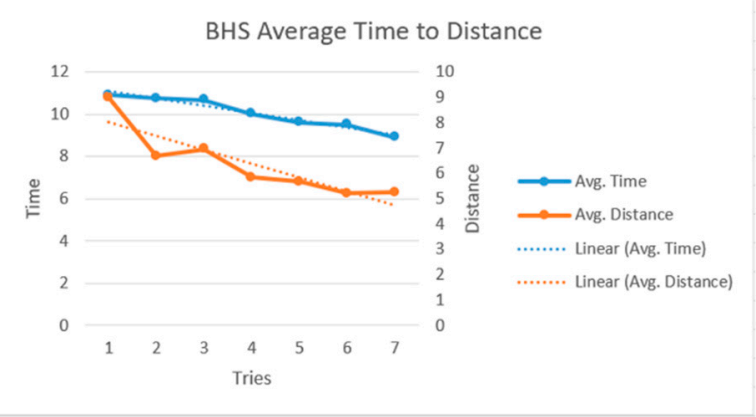

Figure 13. Both hands sine avg. time to distance trend.

\section{Methods (RW)}

\subsection{Equipment}

The same models as in VR were used for the experiment on paper, but this time they were a real glue gun and a caulking gun (see Figures 14 and 15). The sizes of the real models were very similar to the ones in VR, and the drawings on the paper were similar to the 3D models of the lines in VR. Below are shown the real models of the glue gun and caulking gun.

Although the glue gun uses plastic as a glue that melts when attached to an electric socket, in this experiment a pencil lead on the tip of the glue gun was used. This was a much easier solution then using melted plastic and allowed us to get a continuous line on the paper.

The caulking gun had a new unopened silicone tube. Similarly, instead of using silicone for drawing, a small pencil was inserted in the nozzle. This was an easier solution and produced better drawing results. 


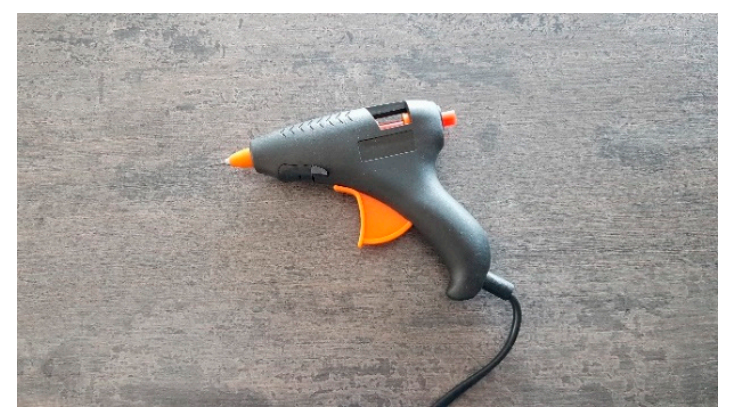

Figure 14. Glue gun with pencil lead inside.

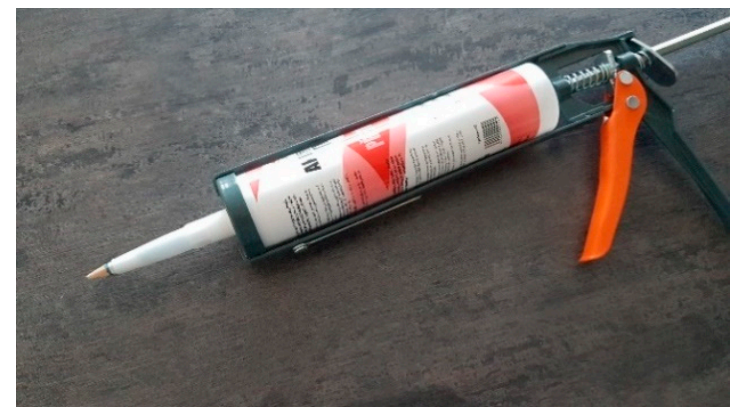

Figure 15. Caulking gun with small pencil attached.

\subsection{Paper/RW Material}

For both sessions for the paper experiment, 5 A4 format sheets of paper were used for each participant.

1. One sheet of paper contained 2 lines on one side for one-hand drawing (glue gun), and 2 lines on the back of the sheet for both-hands drawing (caulking gun).

2. One sheet of paper with 2 circles on both sides for one-hand drawing (glue gun).

3. One sheet of paper with 2 circles on both sides for both-hands drawing (caulking gun).

4. One sheet of paper with 2 sine waves on both sides for one-hand drawing (glue gun).

5. One sheet of paper with 2 sine waves on both sides for both-hands drawing (caulking gun).

In Figures 16-18 are photographs of the paper sheets with red lines drawn on them. In addition, you can see the drawings made by participants with the glue gun and the caulking gun (using pencil). The first number (e.g., 5.7 or 7.3 ) indicates the time in seconds taken to draw the line. The second number (1 or 2) indicates the one-hand (glue gun) or two-hand (caulking gun) test.

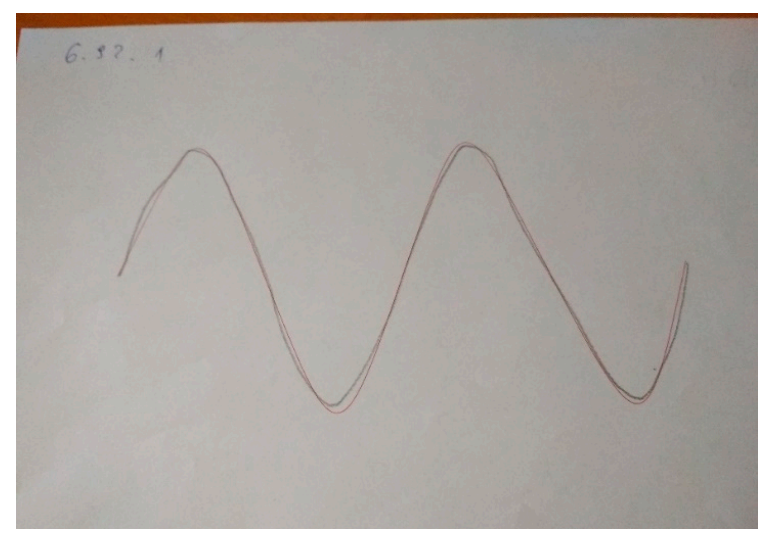

Figure 16. One-hand sine drawing. 


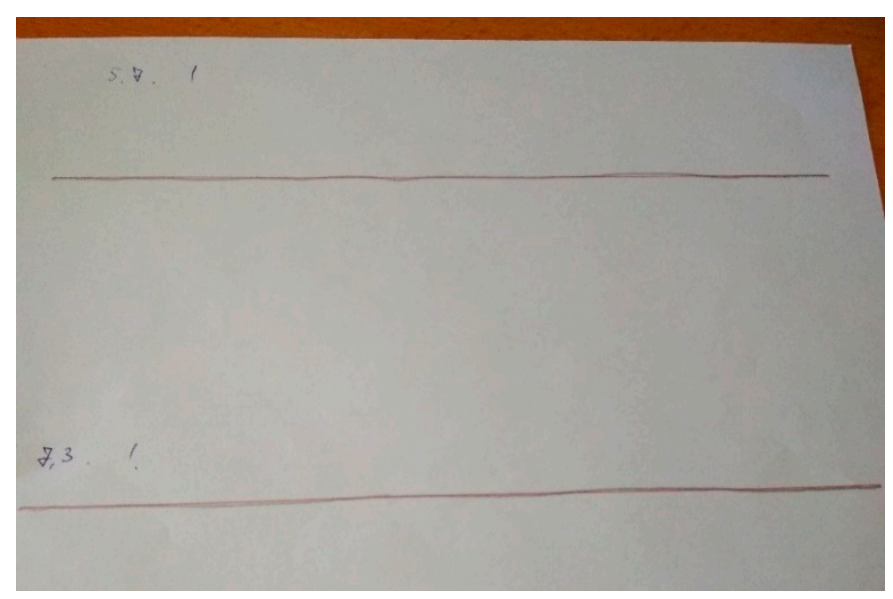

Figure 17. One-hand line drawing.

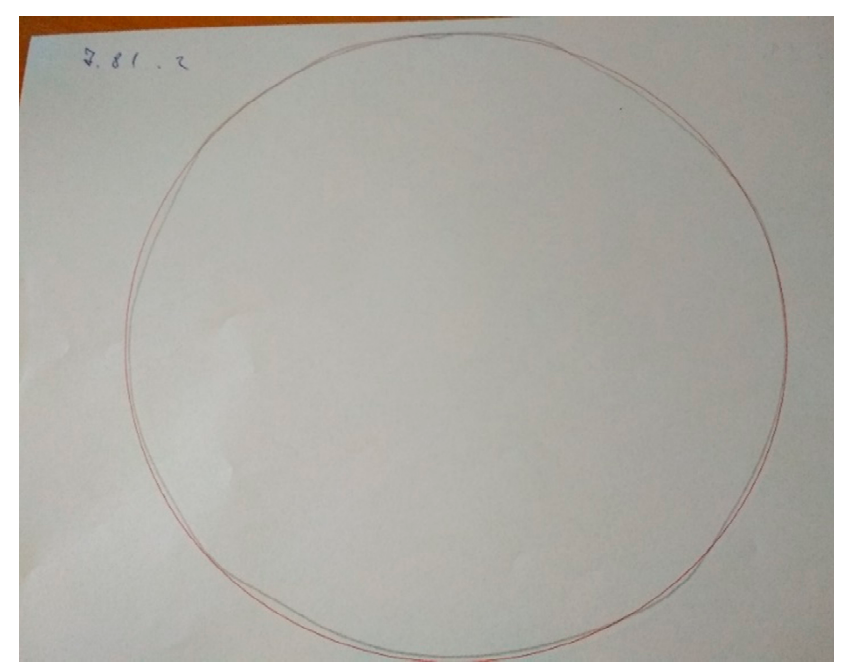

Figure 18. Both-hands circle drawing.

\subsection{Procedure}

Participants were positioned near the table where all the paper materials and glue gun or caulking gun were prepared. Once a participant was given a tool, they proceeded to draw the line on the paper. All participants were instructed to draw the lines onto the prepared red drawings as fast and precisely as possible. Choosing either higher precision or speed was completely up to them. It just needed to be done to the best of their abilities. During the test, the experimenter would hold the paper so that it did not move and also measured the time with a stopwatch. After each drawing, the time to finish the drawing and the test type ( 1 or 2 ) were written down beside each drawing. Then the paper was either changed or turned to continue the process until all the drawings were finished. Overall, the whole process could take around $5 \mathrm{~min}$, depending on the participant's decision to go either for speed or accuracy.

\subsection{Calculations}

Although the experiment on the paper measured the same factors as in VR, doing the calculations here in the same way as with the VR data would be a huge challenge or maybe even impossible. Therefore, a different route was chosen. In order to measure the accuracy of the paper drawings, a transparent plastic sheet was prepared on which was printed each type of shape with multiple points on them, which used as a reference to check if the drawings went through them or not. These covers then were placed onto the actual paper drawing results, and the points were counted. Only the points that touched the drawing 
made by the participant were counted. If the drawn shape (grey) and the red figure had some white space in between, the point was counted as a miss. Below you can see all 3 covers for each drawing. The line cover had 52 points, the circle 112 points, and the sinus 81 points.

Using this transparent sheet (see Figures 19-21), it was possible to accurately calculate the number of points that were present on the drawn lines of the participants. These calculations required the manual tracking of all the points and adding them to the data table. The VR experiment, wherein data was automatically gathered in a Json file, required less manual work. Due to the calculations being done manually, the number of points (density) calculated for the RW paper tests was limited. All the calculations were done by a single person in an objective manner.

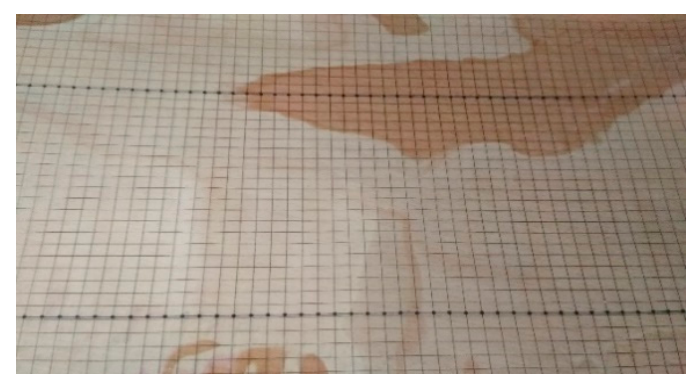

Figure 19. Transparent sheet for line points calculations (paper exp.).



Figure 20. Transparent sheet for sinus points calculations (paper exp.).

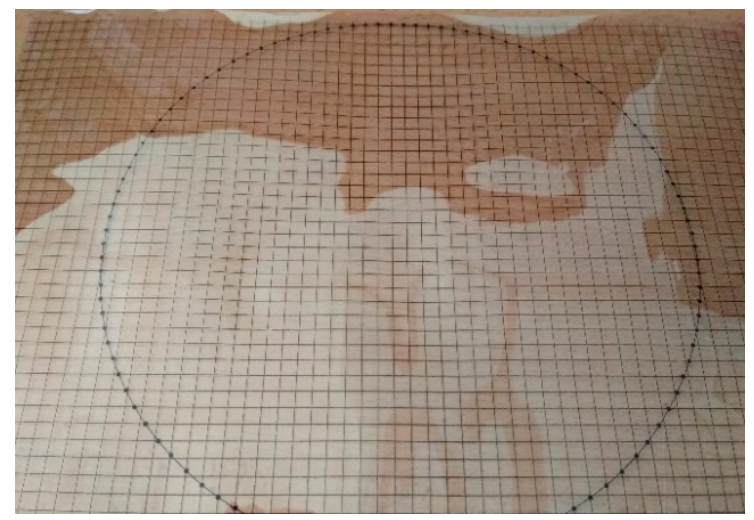

Figure 21. Transparent sheet for circle points calculations (paper exp.).

\section{Results}

Precision in the RW tests was calculated differently from in VR. The more points present on the drawn shape, the higher the score. Figures 22-26 show that the time measurements in seconds are the same as for the VR measurements, but when it comes to precision measurements, we count the number of points that are positioned correctly on the predefined visual shapes on the paper (line, circle, sine). 


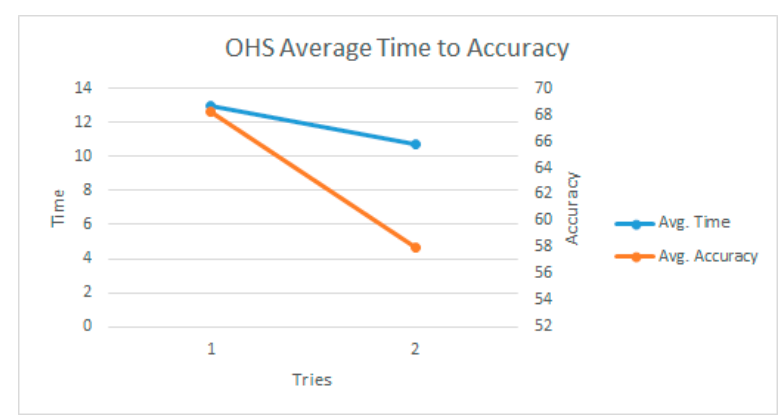

Figure 22. One hand line avg. time to accuracy trend.

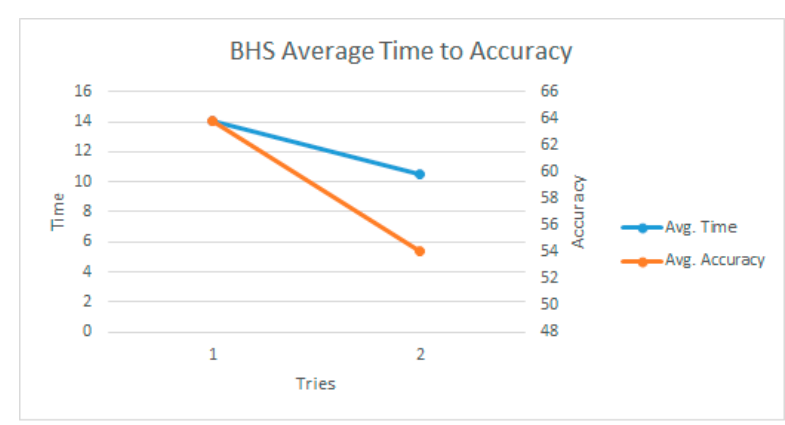

Figure 23. Both hands line avg. time to accuracy trend.

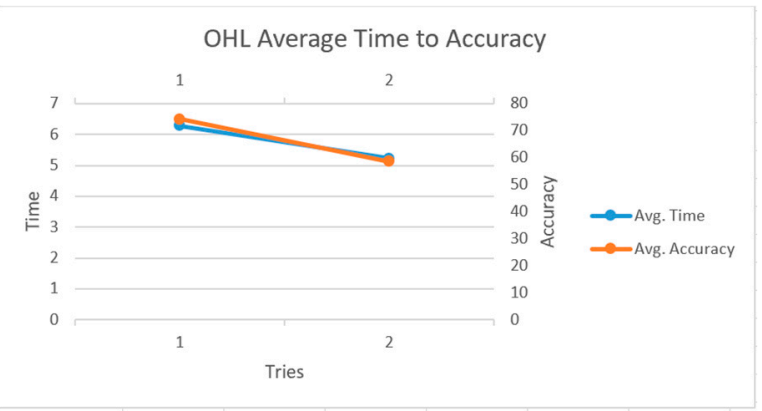

Figure 24. Both hands circle avg. time to accuracy trend.



Figure 25. One hand circle avg. time to accuracy trend. 


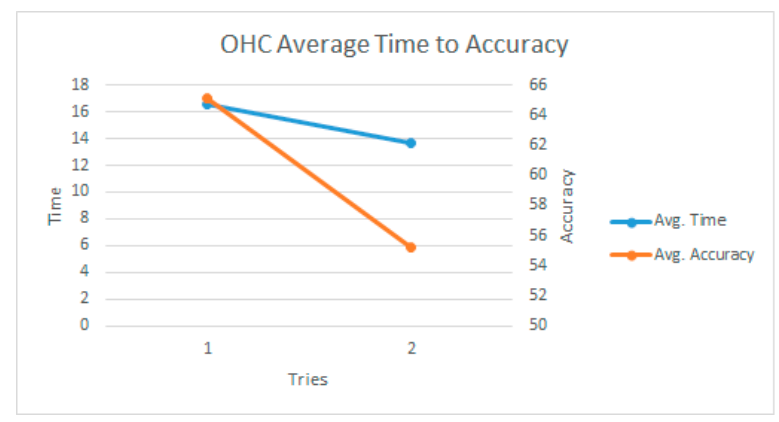

Figure 26. One hand sine avg. time to accuracy trend.

Results from the RW experiments, which were only done twice, on the first and on the last day of the experiment, indicate improvements only in the time variable, whereas the accuracy of the drawing worsened compared to the first attempt. One of the interesting changes that could be incorporated in such an experiment would be adding one more RW test in between the 7 VR tests to see if the results would be the same. Although there are multiple factors, some of the reasons why these results were as they are could be forgetting the RW task, the type of the test itself, lack of motivation, etc.

\section{In-Depth Statistical Evaluation}

MATLAB R2017a software was used for the statistical evaluation. The main goal was to decide if there was a difference between the first and last attempt (VR and paper), in order to see if the participants improved after the process of training in VR.

\subsection{Methodology of Statistical Eevaluation}

Statistical hypothesis testing was used for the statistical processing of the experimental data. A statistical hypothesis is a statement that relates to an unknown property or parameters of the probability distribution of a random variable. In statistical testing, we always have two types of hypotheses:

Hypothesis 1 (H1). Null hypothesis $H_{0}$ means the hypothesis, the validity of which we verify using a test.

Hypothesis 2 (H2). Alternative hypothesis $H_{A}$ means the hypothesis that denies the validity of the null hypothesis.

To test the null hypothesis, we must always choose a significance level $\alpha$, which is the probability of rejection of a true null hypothesis (type I error). We always require this probability to be small, so we choose, according to our habit, to be $\alpha=0.05$. The decision to reject/not-reject the null hypothesis is made using the $p$-value of the test. We reject the null hypothesis if the $p$-value of the test is less than the level of significance. More about hypothesis testing can be found in [37].

Statistical tests are used to verify the validity of the null hypothesis. There are parametric and nonparametric tests. Parametric tests are those for which we must know the distribution of data, and they usually assume a normal distribution. Nonparametric tests do not require this assumption. Three tests were used in this work:

1. Jarque-Bera test

2. Paired-sample $t$-test

3. Wilcoxon signed ranked test

Jarque-Bera test

First, the data obtained were tested for normality using the Jarque-Bera [38] test in order to decide whether we should use parametric or non-parametric statistical tests. 
Parametric tests can only be used for data with normal distribution; non-parametric tests are used for data with different distributions [37].

The Jarque-Bera test tested the null hypothesis that the measured data follow a normal distribution against the alternative hypothesis that the measured data do not follow a normal distribution.

If the $p$-value is greater than the significance level $\alpha=0.05$, we do not reject the null hypothesis of data normality and we can use a parametric test (paired-sample $t$ test). Otherwise, we reject the null hypothesis of data normality, and we have to use a non-parametric test (Wilcoxon signed rank test).

\section{Paired-sample $t$-test}

This paired-sample $t$-test [39] is parametric and can only be used for data that comes from a normal distribution.

We test the null hypothesis that the distribution of the observed variable (time/distance/ accuracy) is identical in both groups (first and last attempt) and has the same mean (expected value) against the alternative hypothesis that the distribution of the observed variables is not identical in both groups and has a different mean.

We reject the null hypothesis if the $p$-value of the test is less than the significance level $\alpha=0.05$, which means that there is a statistically significant difference between the first and last attempt. If we do not reject the null hypothesis, there is no statistically significant difference.

\section{Wilcoxon signed rank test}

If data does not come from a normal distribution, in the next step, we use the parametric Wilcoxon test for two paired samples [40]. It is the non-parametric equivalent of the paired-sample $t$-test. We test that the null hypothesis data in both groups (first and last attempt) are samples from continuous distributions with equal medians against the alternative that they are not.

The method of evaluation and conclusions are the same as for the paired-sample $t$-test.

\subsection{VR Experiment}

Here these two hypotheses were verified:

Hypothesis 3 (H3). Distance-reducing trend (increasing drawing accuracy) for VR testing is to be expected.

Hypothesis 4 (H4). Time-reducing trend (increasing drawing speed) for VR testing is to be expected.

We tested the statistically significant difference between the first and seventh (last) attempt. First, the normality test was done. In Tables 1 and 2, we can see the $p$-values of the test for both observed variables (distance and time) and for all six versions of the experiment.

Table 1. VR distance-Jarque-Bera test.

\begin{tabular}{cccccccccccccc}
\hline VR Distance & \multicolumn{2}{c}{ One Hand Line } & \multicolumn{2}{c}{ One Hand Circle } & \multicolumn{2}{c}{ One Hand Sine } & \multicolumn{3}{c}{ both Hands Line } & \multicolumn{3}{c}{ both Hands Circle } & both Hands Sine \\
\hline Attempt & 1 & 7 & 1 & 7 & 1 & 7 & 1 & 7 & 1 & 7 & 1 & 7 \\
\hline$p$-value & 0.001 & 0.500 & 0.035 & 0.500 & 0.246 & 0.416 & 0.390 & 0.500 & 0.056 & 0.024 & 0.234 & 0.391 \\
\hline
\end{tabular}

Table 2. VR time-Jarque-Bera test.

\begin{tabular}{cccccccccccccc}
\hline VR Time & \multicolumn{2}{c}{ One Hand Line } & \multicolumn{2}{c}{ One Hand Circle } & \multicolumn{2}{c}{ One Hand Sine } & \multicolumn{2}{c}{ both Hands Line } & \multicolumn{3}{c}{ both Hands Circle } & both Hands Sine \\
\hline Attempt & 1 & 7 & 1 & 7 & 1 & 7 & 1 & 7 & 1 & 7 & 1 \\
\hline$p$-value & 0.002 & 0.041 & 0.500 & 0.018 & 0.500 & 0.323 & 0.500 & 0.369 & 0.173 & 0.255 & 0.153 & 0.051 \\
\hline
\end{tabular}

As can be seen, the $p$-value was in some cases lower than the significance level $\alpha=0.05$. This means that not all the data sets come from a normal distribution. Therefore, 
the non-parametric Wilcoxon signed rank test was used. It was tested whether there was a difference in significance level between the first and last attempt of the VR experiment for all the variants (one hand/both hands, line/circle/sinus wave).

In Table 3, we can see the results for the distance variable. The $p$-value is lower than the significance level $\alpha=0.05$ for all variants. This means that we reject the null hypothesis and that there is a statistically significant difference between the first and last attempt. We know from Figures 8-13 that the average values of the distance variable decreased. This test confirmed this change with a significance level $\alpha=0.05$, and this means that the drawing accuracy increased, and Hypothesis H1 is confirmed.

Table 3. VR Distance-Wilcoxon signed rank test.

\begin{tabular}{ccccccc}
\hline VR Distance & One Hand Line & One Hand Circle & One Hand Sine & both Hands Line & both Hands Circle & both Hands Sine \\
\hline$p$-value & 0.002 & 0.001 & 0.004 & 0.006 & 0.002 & 0.001 \\
\hline
\end{tabular}

Table 4 shows the results for the time variable. Again, in all cases the $p$-value was lower than the significance level $\alpha=0.05$. This means that we reject the null hypothesis and that there is a statistically significant difference between the first and last attempt. As we know from Figures 8-13, this difference is the shorter time in the last attempt than in the first. This confirms Hypothesis $\mathrm{H} 2$ about the expected time-reducing trend (increasing drawing speed) for VR testing.

Table 4. VR time-Wilcoxon signed rank test.

\begin{tabular}{ccccccc}
\hline VR Time & One Hand Line & One Hand Circle & One Hand Sine & both Hands Line & both Hands Circle & both Hands Sine \\
\hline$p$-value & 0.030 & 0.023 & 0.024 & 0.026 & 0.006 & 0.026 \\
\hline
\end{tabular}

Real world experiment

In the real world experiment, these two hypotheses were verified:

Hypothesis 5 (H5). Accuracy-increasing trend for RW tests (on paper) is to be expected.

Hypothesis 6 (H6). Time-reducing trend (increasing drawing speed) for $R W$ tests (on paper) is to be expected.

As in the VR experiment, the difference was tested between the first and last (second) attempts. First, the normality test was done. The results of the normality test can be seen in Tables 5 and 6 for all versions of the experiment.

Table 5. Paper accuracy-Jarque-Bera test.

\begin{tabular}{cccccccccccccc}
\hline $\begin{array}{c}\text { Paper } \\
\text { Accuracy }\end{array}$ & One Hand Line & \multicolumn{2}{c}{$\begin{array}{c}\text { One Hand } \\
\text { Circle }\end{array}$} & One Hand Sine & $\begin{array}{c}\text { both Hands } \\
\text { Line }\end{array}$ & \multicolumn{2}{c}{$\begin{array}{c}\text { both Hands } \\
\text { Circle }\end{array}$} & both Hands Sine \\
\hline Attempt & $\mathbf{1}$ & $\mathbf{2}$ & $\mathbf{1}$ & $\mathbf{2}$ & $\mathbf{1}$ & $\mathbf{2}$ & $\mathbf{1}$ & $\mathbf{2}$ & $\mathbf{1}$ & $\mathbf{2}$ & $\mathbf{1}$ & $\mathbf{2}$ \\
\hline$p$-value & 0.043 & 0.500 & 0.016 & 0.435 & 0.488 & 0.162 & 0.035 & 0.500 & 0.135 & 0.500 & 0.371 & 0.185 \\
\hline
\end{tabular}

Table 6. Paper time--Jarque-Bera test.

\begin{tabular}{cccccccccccccc}
\hline $\begin{array}{c}\text { Paper } \\
\text { Time }\end{array}$ & \multicolumn{2}{c}{ One Hand Line } & \multicolumn{2}{c}{$\begin{array}{c}\text { One Hand } \\
\text { Circle }\end{array}$} & One Hand Sine & \multicolumn{2}{c}{$\begin{array}{c}\text { both Hands } \\
\text { Line }\end{array}$} & \multicolumn{3}{c}{$\begin{array}{c}\text { both Hands } \\
\text { Circle }\end{array}$} & \multicolumn{2}{c}{ both Hands Sine } \\
\hline Attempt & 1 & 2 & 1 & 2 & 1 & 2 & 1 & 2 & 1 & 2 & 1 \\
\hline$p$-value & 0.089 & 0.086 & 0.471 & 0.144 & 0.500 & 0.209 & 0.052 & 0.224 & 0.358 & 0.118 & 0.206 & 0.143 \\
\hline
\end{tabular}


In the case of the accuracy variable, see Table 5. The $p$-value was in some cases lower than the significance level $\alpha=0.05$. This means that not all of the data sets come from a normal distribution. Therefore, the non-parametric Wilcoxon signed rank test was used.

In the case of the time variable, see Table 6. All $p$-values were greater than the significance level $\alpha=0.05$; we do not reject the null hypothesis of data normality, and we can use the paired-sample $t$-test.

In Table 7 , we can see the results for the accuracy variable. The $p$-value was lower than the significance level $\alpha=0.05$ in the case of the one-hand line and circle and the both-hands line. This means that, in these cases, there was a statistically significant difference between the first and second attempt. As we know from Figures 22-24, this difference was in the reduction in accuracy. This is the opposite of what we assumed. In the other versions of the experiment, we did not reject the null hypothesis, so there was no statistically significant difference between the first and second attempt. This means that accuracy did not decrease significantly in these cases, but neither did it improve. Hypothesis H1 was therefore not confirmed.

Table 7. Paper accuracy-Wilcoxon signed rank test.

\begin{tabular}{ccccccc}
\hline Paper & One Hand & One Hand & One Hand & both Hands & both Hands & both Hands \\
Accuracy & Line & Circle & Sine & Line & Circle & Sine \\
\hline$p$-value & 0.011 & 0.034 & 0.083 & 0.020 & 0.063 & 0.095 \\
\hline
\end{tabular}

Table 8 shows the results ( $p$-values) of the paired-sample $t$-test for the time variable. Based on the results, we can say that there is a significant difference between attempts 1 and 2 in the case of the one-hand circle, sinus wave, and both-hands line, circle, and sinus wave, with a significance level $\alpha=0.05 \%$. There is not a significant difference between the first and second attempt in the experiment with the one-hand line at the significance level $\alpha=0.05 \%$ (but there is at the level 0.1\%). As we know from Figures 23-27, the trend of the time variable declined in all cases. This means that we have confirmed Hypothesis $\mathrm{H} 2$ in all versions of the experiment with the exception of the one-hand line at the significance level $\alpha=0.05 \%$. However, even in this case, it can be seen from Figure 22 that some improvement has taken place, so we can confirm the Hypothesis $\mathrm{H} 2$ for this version as well but at the significance level of 0.1 (a higher level of uncertainty).

Table 8. Paper time-paired-sample $t$-test.

\begin{tabular}{ccccccc}
\hline Paper Time & $\begin{array}{c}\text { One Hand } \\
\text { Line }\end{array}$ & $\begin{array}{c}\text { One Hand } \\
\text { Circle }\end{array}$ & $\begin{array}{c}\text { One Hand } \\
\text { Sine }\end{array}$ & $\begin{array}{c}\text { both Hands } \\
\text { Line }\end{array}$ & $\begin{array}{c}\text { both Hands } \\
\text { Circle }\end{array}$ & $\begin{array}{c}\text { both Hands } \\
\text { Sine }\end{array}$ \\
\hline$p$-value & 0.091 & 0.021 & 0.041 & 0.016 & 0.018 & 0.014 \\
\hline
\end{tabular}

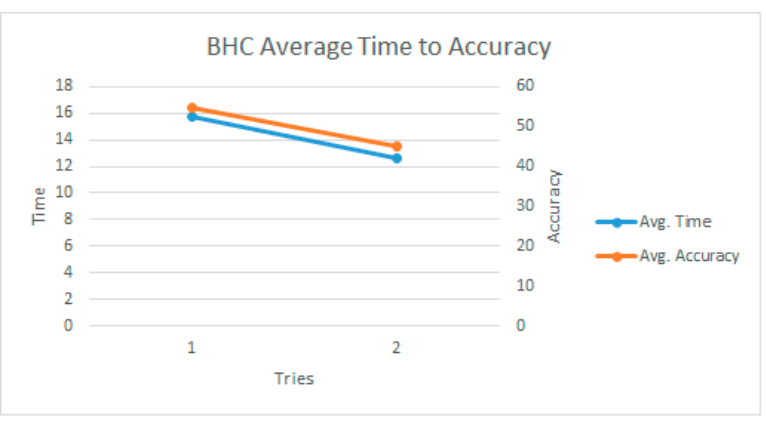

Figure 27. Both hands sine avg. time to accuracy trend.

\section{Discussion}

The main point of this work was to discover the effects/benefits of using virtual reality for training. The training was focused on improvements to the precision of hand 
movements using a specific type of VR simulation that would allow users/participants to perform similar movement tasks over a prolonged period of time (approximately one month). As VR is said to be a very effective technology in this sphere, we created a VR simulation using the Unity3D game engine for this experiment. This engine proved itself to be very powerful and easy to use, as it had already been used for other types of simulations prior to this.

The simulation for this work took several months to prepare and conduct. In addition to VR tests, RW experiments also took place. VR tests took place in seven sessions, whereas there were only two RW tests, on the start and end dates of the experiment. This was done to analyse the effects of training not only in VR itself but also the transfer of skills to the RW.

Once the experiment was done, the data were collected. VR data was gathered inside the Unity3D game engine during the test process itself. Then the data about precision (in Json format) were exported to Excel, where they were processed in pre-prepared macro templates. RW data on performing the line movements (line, circle, sine wave) was processed at the end of the experiment. Lastly, RW data was exported to Excel templates, and the precision results were calculated and analysed using specific macros.

The results suggest very positive outcomes for VR training in particular. As the participants had to perform on each of seven sessions four attempts of each type of simulation (six overall: one hand/two hands, line/circle/sine wave); in the end, the results improved drastically, and they actually improved from the start to the end. It was pointed out that possibly only four training sessions for this type of training could be sufficient as, after the fourth attempt, although there were improvements, they were not that impressive.

When it comes to the RW tests, the results suggest that the transfer of skill from VR to RW was only partial. A study suggested similar results, wherein the training in VR produced positive results in that virtual scenario, but when it came to transferring the training to the RW scenario, no significant or no benefits were found [41]. Only the time value improved from the first attempt compared to the second one. Multiple reasons were suggested for this, such as participant forgetfulness, noninterest, tiredness, etc. It is recommended to perform such an experiment with a much bigger pool of participants, in-depth questionnaires, and possibly perform RW tests more frequently between the VR tests to remind the participants what they are training for. Additionally, it could also be the type of simulation that resulted in these outcomes. In order to be sure about some factors that could cause these non-beneficial effects, more research and experimentation should be performed on top of this work.

As this experiment and training look very similar to welding training simulations, it is interesting to point out a couple of studies that delved into training participants in this field and evaluated the transfer of that training to practical cases.

A study [42] suggests that VR welding simulations are good not only for novice welders but also for experienced ones as well. The training in VR welding is then used in practice in RW cases. As the results show some difference in quality between novice and experienced welders, data also suggests that even experienced welders can struggle with higher difficulty welds in VR, which can in turn allow them to train and become better at new levels. Thus, suggesting that there is a positive correlation and transfer of skills from VR training to the real world depending on the simulation type/difficulty.

On the other hand, research [43] on different types of welding difficulty tasks shows that, the higher the difficulty of the welding task in VR, the less effective VR training becomes, thus requiring supplementary RW training. But for easy and medium types of training difficulty, VR is considered to be a great tool, which suggests a positive outcome in the transfer of skills.

It is important to note that the weight factor can play some role in the fatigue and performance of the participants during the tests. In our experiment, all the participants were young and healthy, thus using controllers in VR and simple common tools which did not exceed a weight of $1 \mathrm{~kg}$ (caulking gun—both hands), with the duration of the 
experiment for a maximum of $15 \mathrm{~min}$ with breaks if needed, would not cause a significant hurdle for the participants to perform the task they were given.

Although the weight of the two controllers and the caulking gun were almost the same (the caulking gun was slightly heavier), and one controller had almost the same weight as the glue gun, there was no significant point in conducting the experiment in VR and RW with identical weights. The experiment was very similar in some ways both in VR and RW, but some things-weight, controller vs. RW tool, etc. - could not be matched identically, thus measuring the effect of the weight difference on the result was not one of our goals. One possibility would be to use a tracker mounted on the tool instead of the controller, which could give better results, as the grip feeling and weight in VR and RW tests would be almost identical. The results of such tests would and should definitely give different results.

This experiment was just a preliminary test of such a type of training in VR. Initially, the analysis and conclusions may look rough, but to make them more fine-tuned, more such tests should be performed and in different variations. Those results will then be compared, and more precise and expanded versions of the outcomes could be discussed. In this case, seven tests in VR were performed, whereas in the RW, there were only two. Initially, the idea to perform the RW test on the start date and end date of the VR tests seemed sufficient, and the results were believed to be more positive. As it came out at the end, the results in the RW tests were not so satisfactory, which suggests many different ideas, such as the type of the experiment, lack of repetitions, etc. The only way to answer those ideas precisely is to repeat the same and different experiments multiple times, with different variables.

This work suggested using this type of training only in one way. Using information from this work and performing similar research could eventually result in different outcomes. Those outcomes then would be used to prove some other important points about using VR for training and its benefits. As mentioned, the difficulty of the simulation and supplementary RW training could play a big role in the transfer of skills. Future work should be targeted at delving into the factors described above more deeply, in order to prove or disprove the hypothesis.

\section{Conclusions}

Four hypotheses were tested using statistical hypothesis testing and set out in Section 6 . VR experiment

Hypothesis 3 (H3). Distance-reducing trend (increasing drawing accuracy) for VR testing is to be expected.

Hypothesis 4 (H4). Time-reducing trend (increasing drawing speed) for VR testing is to be expected.

Results: Both hypotheses were confirmed. There were statistically significant changes (in terms of improvement) for both the monitored variables (distance, time).

Real world experiment

Hypothesis 5 (H5). Accuracy-increasing trend for RW tests (on paper) is to be expected.

Hypothesis 6 (H6). Time-reducing trend (increasing drawing speed) for RW tests (on paper) is to be expected.

Results: Only Hypothesis $\mathrm{H} 2$ was confirmed for the time variable. There was no change or a change for the worse for the accuracy variable.

Author Contributions: Conceptualization, S.M. and P.H.; methodology, P.H., P.K. and M.B.; software, S.M.; validation, P.K., S.M. and M.B.; formal analysis, S.M. and P.H.; investigation, S.M.; resources, S.M., P.H. and M.Š.; data curation, S.M.; writing—original draft preparation, S.M.; writing—review 
and editing, S.M., P.H. and M.B.; visualization, S.M. and P.H.; supervision, P.H. and P.K.; project administration, M.Š.; funding acquisition, M.Š. All authors have read and agreed to the published version of the manuscript.

Funding: This work was supported by the Internal Science Foundation of the University of West Bohemia under Grant SGS-2021-028 Developmental and Training Tools for the Interaction of Man and the Cyber-Physical Production System' and with the financial support of the European Union, as part of the project entitled development of capacities and environment for boosting the international, intersectoral and interdisciplinary cooperation, project reg. No. CZ.02.2.69/0.0/0.0/18_054/0014627.

Institutional Review Board Statement: The study was approved by the internal university Ethics Committee.

Informed Consent Statement: Informed consent was obtained from all subjects involved in the study.

Data Availability Statement: https:/ /drive.google.com/file/d/1pgmPETqm7QhgJMjGUAEhG3 ChctiVkML0/view? usp=sharing (accessed on 26 August 2021).

Conflicts of Interest: The authors declare no conflict of interest.

\section{References}

1. Accuracy, vs. Precision. Available online: https://www.forecast.app/faqs/what-is-the-difference-between-accuracy-andprecision (accessed on 29 March 2021).

2. Thurman, R.A. Instructional simulation from a cognitive psychology viewpoint. Educ. Technol. Res. Dev. 1993, 41, 75-89. [CrossRef]

3. Rieber, L.P. Computer-based micro worlds: A bridge between constructivism and direct instruction. Educ. Technol. Res. Dev. 1992, 40, 93-106. [CrossRef]

4. Abulrub, A.G.; Attridge, A.N.; Williams, M.A. Virtual reality in engineering education: The future of creative learning. In Proceedings of the Global Engineering Education Conference (EDUCON), Amman, Jordan, 4-6 April 2011; pp. 751-757. [CrossRef]

5. Gregory, S.; Gregory, B.; Reiners, T.; Fardinpour, A.; Hillier, M.; Lee, M.; Basu, A. Virtual worlds in Australian and New Zealand higher education: Remembering the past, understanding the present and imagining the future. In Proceedings of the ASCILITE 2013 “Electric Dreams”, Sydney, Australia, 1-4 December 2013; Macquarie University: Sydney, NSW, Australia, 2013. ISBN 9781741384031.

6. Jou, M.; Wang, J. Investigation of effects of virtual reality environments on learning performance of technical skills. Comput. Hum. Behav. 2013, 29, 433-438. [CrossRef]

7. Wilson, J.R. Virtual environments and ergonomics: Needs and opportunities. Ergonomics 1997, 40, 1057-1077. [CrossRef]

8. Mitchell, P.; Parsons, S.; Leonard, A. Using virtual environments for teaching social understanding to 6 adolescents with autistic spectrum disorders. J. Autism Dev. Disord. 2007, 37, 589-600. [CrossRef]

9. Cheng, Y.; Wang, S.H. Applying a 3D virtual learning environment to facilitate student's application ability-the case of marketing. Comput. Hum. Behav. 2011, 27, 576-584. [CrossRef]

10. Bertram, J.; Moskaliuk, J.; Cress, U. Virtual training: Making reality work? Comput. Hum. Behav. 2015, 43, 284-292. [CrossRef]

11. Dede, C. Millennial learning styles. Educ. Q. 2005, 28, 7-12.

12. Dede, C. Immersive interfaces for engagement and learning. Science 2009, 323, 66-69. [CrossRef]

13. Hořejší, P. Augmented Reality System for Virtual Training of Parts Assembly. Procedia Eng. 2015, 100, 699-706. [CrossRef]

14. Hořejší, P.; Novikov, K.; Šimon, M. A Smart Factory in a Smart City: Virtual and Augmented Reality in a Smart Assembly Line. IEEE Access 2020, 8, 94330-94340. [CrossRef]

15. American Psychiatric Association. Diagnostic and Statistical Manual of Mental Disorders, 4th ed.; American Psychiatric Association: Washington, DC, USA, 2000; ISBN 0-89042-062-9.

16. Hooper, S.R.; Poon, K.K.; Marcus, L.; Fine, C. Neuropsychological characteristics of school-age children with high-functioning autism: Performance on the NEPSY. Child Neuropsychol. 2006, 12, 299-305. [CrossRef]

17. Merchant, Z.; Goetz, E.T.; Cifuentes, L.; Keeney-Kennicutt, W.; Davis, T.J. Effectiveness of virtual reality-based instruction on students' learning outcomes in K-12 and higher education: A meta-analysis. Comput. Educ. 2014, 70, 29-40. [CrossRef]

18. Lee EA, L.; Wong, K.W. Learning with desktop virtual reality: Low spatial ability learners are more positively affected. Comput. Educ. 2014, 79, 49-58. [CrossRef]

19. Nicholson, D.T.; Chalk, C.; Funnell WR, J.; Daniel, S.J. Can virtual reality improve anatomy education? A randomised controlled study of a computer-generated three-dimensional anatomical ear model. Med. Educ. 2006, 40, 1081-1087. [CrossRef]

20. Hettinger, L.J.; Riccio, G.E. Visually Induced Motion Sickness in Virtual Environments. Presence Teleoperators Virtual Environ. 1992, 1, 306-310. [CrossRef]

21. Lackey, S.J.; Salcedo, J.N.; Szalma, J.L.; Hancock, P.A. The stress and workload of virtual reality training: The effects of presence, immersion and flow. Ergonomics 2016, 59, 1060-1072. [CrossRef] [PubMed] 
22. Kim, E.; Shin, G. User discomfort while using a virtual reality headset as a personal viewing system for text-intensive office tasks. Ergonomics 2021. [CrossRef]

23. Kuze, J.; Ukai, K. Evaluation of Visual Fatigue Caused by Motion Images; Elsevier: Amsterdam, The Netherlands, 2008; Volume 29, pp. 159-166. [CrossRef]

24. Seay, A.F.; Krum, D.M.; Hodges, L.; Ribarsky, W. Simulator Sickness and Presence in a High FOV Virtual Environment. In Proceedings of the IEEE Virtual Reality Conference 2001 (VR2001), Yokohama, Japan, 13-17 March 2001; pp. 299-300. [CrossRef]

25. Chompoonuch, J.; Kazuhiko, H. Study on Parallax Affect on Simulator Sickness in One-Screen and Three-screen Immersive Virtual Environment. Sch. Inf. Telecommun. Eng. 2011, 4, 34-39.

26. Arns, L.L.; Cerney, M.M. The Relationship Between Age and Incidence of Cyber sickness Among Immersive Environment Users. In Proceedings of the IEEE Virtual Reality, Bonn, Germany, 12-16 March 2005; pp. 267-268. [CrossRef]

27. Parsons, T.D.; Larson, P.; Kratz, K.; Thiebaux, M.; Bluestein, B.; Buckwalter, J.G.; Rizzo, A.A. Sex Differences in Mental Rotation and Spatial Rotation in a Virtual Environment. Neuropsychologia 2004, 42, 555-562. [CrossRef]

28. Suma, E.A.; Finkelstein, S.L.; Clark, S.; Goolkasian, P.; Hodges, L.F. Effects of Travel Technique and Gender on a Divided Attention Task in a Virtual Environment. In Proceedings of the IEEE Symposium on 3D User Interface, Waltham, MA, USA, 20-21 March 2010; pp. 27-34. [CrossRef]

29. Dizio, P.; Lackner, J.R. Alleviation of Motion Sickness and Postural Instability during and after Virtual Environment Exposure; Technical Report; Prepared for Naval Air Warfare Center Training Systems Division: Orlando, FL, USA, 1998.

30. Regan, E.; Price, K. The Frequency and Occurrence and Severity of Side-Effects of Immersion in Virtual Reality. Aviat. Space Environ. Med. 1994, 65, 527-530.

31. Bowman, D.; Kruijff, E.; LaViola, J.J.; Poupyrev, I. An introduction to 3-D user interface design. Teleoperators Virtual Environ. 2001, 10, 96-108. [CrossRef]

32. Rich, C.J.; Braun, C.C. Assessing the impact of control and sensory compatibility on sickness in virtual environments. In Proceedings of the Human Factors and Ergonomics Society 40th Annual Meeting, Philadelphia, PA, USA, 2-6 September 1996. [CrossRef]

33. Hale, K.S.; Stanney, K.M. Handbook of Virtual Environments; Earlbaum: New York, NY, USA, 2002; ISBN 9780805832709.

34. Lathan, R. Tutorial: A brief introduction to simulation sickness and motion programming. Real Time Graph. 2001, 9, 3-5.

35. Michael, P. Motion Sick in Cyberspace. IEEE Comput. Graph. Appl. 1998, 18, 16-21. [CrossRef]

36. Mullen, G.; Davidenko, N. Time Compression in Virtual Reality. Timing Time Percept. 2021, 9, 1-16. [CrossRef]

37. Reif, J. Methods of Mathematical Statistics; University of West Bohemia, Faculty of Applied Sciences: Plzeň, Czech Republic, 2004; pp. 52-76, 157-169. ISBN 80-7043-302-7.

38. Jarque-Bera Test-MATLAB jbtest. MathWorks-Makers of MATLAB and Simulink-MATLAB \& Simulink. Available online: https:/ / www.mathworks.com/help/stats/jbtest.html (accessed on 9 February 2021).

39. One-Sample and Paired-Sample t-Test-MATLAB t-Test. MathWorks-Makers of MATLAB and Simulink-MATLAB \& Simulink. Available online: https:/ / www.mathworks.com/help/stats/ttest.html (accessed on 9 February 2021).

40. Wilcoxon Signed Rank Test-MATLAB Signrank. MathWorks-Makers of MATLAB and Simulink-MATLAB \& Simulink. Available online: https://www.mathworks.com/help/stats/signrank.html (accessed on 9 February 2021).

41. Kozak, J.J.; Hancock, P.A.; Arthur, E.J.; Chrysler, S.T. Transfer of training from virtual reality. Ergonomics 1993, 36, 777-784. [CrossRef]

42. Byrd, A.P.; Anderson, R.G.; Stone, R. The Use of Virtual Welding Simulators to Evaluate Experienced Welders; Industrial and Manufacturing Systems Engineering Publications. 2015, p. 114. Available online: https://lib.dr.iastate.edu/imse_pubs/114 (accessed on 26 August 2021).

43. McLaurin, E.J.; Stone, R.T. Comparison of Virtual Reality Training vs. Integrated Training in the Development of Physical Skills. Proc. Hum. Factors Ergon. Soc. Annu. Meet. 2012, 56, 2532-2536. [CrossRef] 